\title{
Mitogenomic phylogeny of Callithrix with special focus on human transferred taxa
}

\author{
Joanna Malukiewicz ${ }^{1,2^{*}}$ (D) Reed A. Cartwright ${ }^{3}$, Nelson H. A. Curi ${ }^{4}$, Jorge A. Dergam ${ }^{5}$, Claudia S. Igayara ${ }^{6}$, \\ Silvia B. Moreira ${ }^{7}$, Camila V. Molina ${ }^{8,9}$, Patricia A. Nicola ${ }^{10}$, Angela Noll ${ }^{1}$, Marcello Passamani ${ }^{11}$, Luiz C. M. Pereira ${ }^{12}$, \\ Alcides Pissinatti ${ }^{7}$, Carlos R. Ruiz-Miranda ${ }^{13}$, Daniel L. Silva ${ }^{14}$, Anne C. Stone ${ }^{15,16,17}$ (D), Dietmar Zinner ${ }^{18,19,20}$ (D) and \\ Christian Roos ${ }^{1,21}$ (D)
}

\begin{abstract}
Callithrix marmosets are a relatively young primate radiation, whose phylogeny is not yet fully resolved. These primates are naturally para- and allopatric, but three species with highly invasive potential have been introduced into the southeastern Brazilian Atlantic Forest by the pet trade. There, these species hybridize with each other and endangered, native congeners. We aimed here to reconstruct a robust Callithrix phylogeny and divergence time estimates, and identify the biogeographic origins of autochthonous and allochthonous Callithrix mitogenome lineages. We sequenced 49 mitogenomes from four species (C. aurita, C. geoffroyi, C. jacchus, C. penicillata) and anthropogenic hybrids (C. aurita $\times$ Callithrix sp., C. penicillata $\times$ C. jacchus, Callithrix sp. $\times$ Callithrix sp., C. penicillata $\times$ C. geoffroyi) via Sanger and whole genome sequencing. We combined these data with previously published Callithrix mitogenomes to analyze five Callithrix species in total.
\end{abstract}

Results: We report the complete sequence and organization of the C. aurita mitogenome. Phylogenetic analyses showed that C. aurita was the first to diverge within Callithrix 3.54 million years ago (Ma), while C. jacchus and C. penicillata lineages diverged most recently $0.5 \mathrm{Ma}$ as sister clades. MtDNA clades of C. aurita, C. geoffroyi, and C. penicillata show intraspecific geographic structure, but $C$. penicillata clades appear polyphyletic. Hybrids, which were identified by phenotype, possessed mainly C. penicillata or C. jacchus mtDNA haplotypes. The biogeographic origins of mtDNA haplotypes from hybrid and allochthonous Callithrix were broadly distributed across natural Callithrix ranges. Our phylogenetic results also evidence introgression of $C$. jacchus mtDNA into C. aurita.

Conclusion: Our robust Callithrix mitogenome phylogeny shows C. aurita lineages as basal and C. jacchus lineages among the most recent within Callithrix. We provide the first evidence that parental mtDNA lineages of anthropogenic hybrid and allochthonous marmosets are broadly distributed inside and outside of the Atlantic Forest. We also show evidence of cryptic hybridization between allochthonous Callithrix and autochthonous C. aurita. Our results encouragingly show that further development of genomic resources will allow to more clearly elucidate Callithrix evolutionary relationships and understand the dynamics of Callithrix anthropogenic introductions into the Brazilian Atlantic Forest.

Keywords: mtDNA, Marmoset, Divergence, Atlantic forest, Brazil, Callitrichidae, Primate

\footnotetext{
*Correspondence: jmalukiewicz@dpz.eu

'Primate Genetics Laboratory, German Primate Center, Leibniz Institute for Primate Research, Göttingen, Germany

${ }^{2}$ Instituto de Medicina Tropical de São Paulo, Universidade de São Paulo, São Paulo, SP, Brazil

Full list of author information is available at the end of the article
}

(c) The Author(s). 2021 Open Access This article is licensed under a Creative Commons Attribution 4.0 International License, which permits use, sharing, adaptation, distribution and reproduction in any medium or format, as long as you give appropriate credit to the original author(s) and the source, provide a link to the Creative Commons licence, and indicate if changes were made. The images or other third party material in this article are included in the article's Creative Commons licence, unless indicated otherwise in a credit line to the material. If material is not included in the article's Creative Commons licence and your intended use is not permitted by statutory regulation or exceeds the permitted use, you will need to obtain permission directly from the copyright holder. To view a copy of this licence, visit http://creativecommons.org/licenses/by/4.0/. The Creative Commons Public Domain Dedication waiver (http://creativecommons.org/publicdomain/zero/1.0/) applies to the data made available in this article, unless otherwise stated in a credit line to the data. 


\section{Background}

Callithrix species represent a relatively young radiation, and divergence among lineages within the genus is estimated to be between approximately 0.7 and 2.5 million years ago (Ma) [1-3]. Two major subgroups occur within the genus, the aurita group (C. aurita/C. flaviceps) and the jacchus group (C. geoffroyi/C. kuhlii/C. jacchus/C. penicillata), but the phylogeny of these lineages is not yet fully resolved. Callithrix species are naturally para- and allopatric across the Brazilian Atlantic Forest, Cerrado, and Caatinga biomes (Fig. 1) [4, 5], and natural hybridization occurs between some species [6]. However, C. geoffroyi, C. jacchus, and C. penicillata have high invasive potential $[7,8]$ and have spread widely outside of their native ranges due to the legal and illegal pet trades. These species have established several allochthonous populations in the southeastern Brazilian Atlantic Forest $[6,9,10]$ and hybridize with other allochthonous and autochthonous congeners [6, 9-11], including endangered C. aurita and C. flaviceps [12,13]. Yet, determining evolutionary relationships between autochthonous, allochthonous, and hybrid Callithrix populations across Brazil is complicated by the unresolved Callithrix phylogeny.

In general, mitochondrial DNA (mtDNA) can be utilized for an initial look into evolutionary relationships among taxa (e.g., $[14,15])$ as well as track dispersal and gene flow patterns of allochthonous species [16].

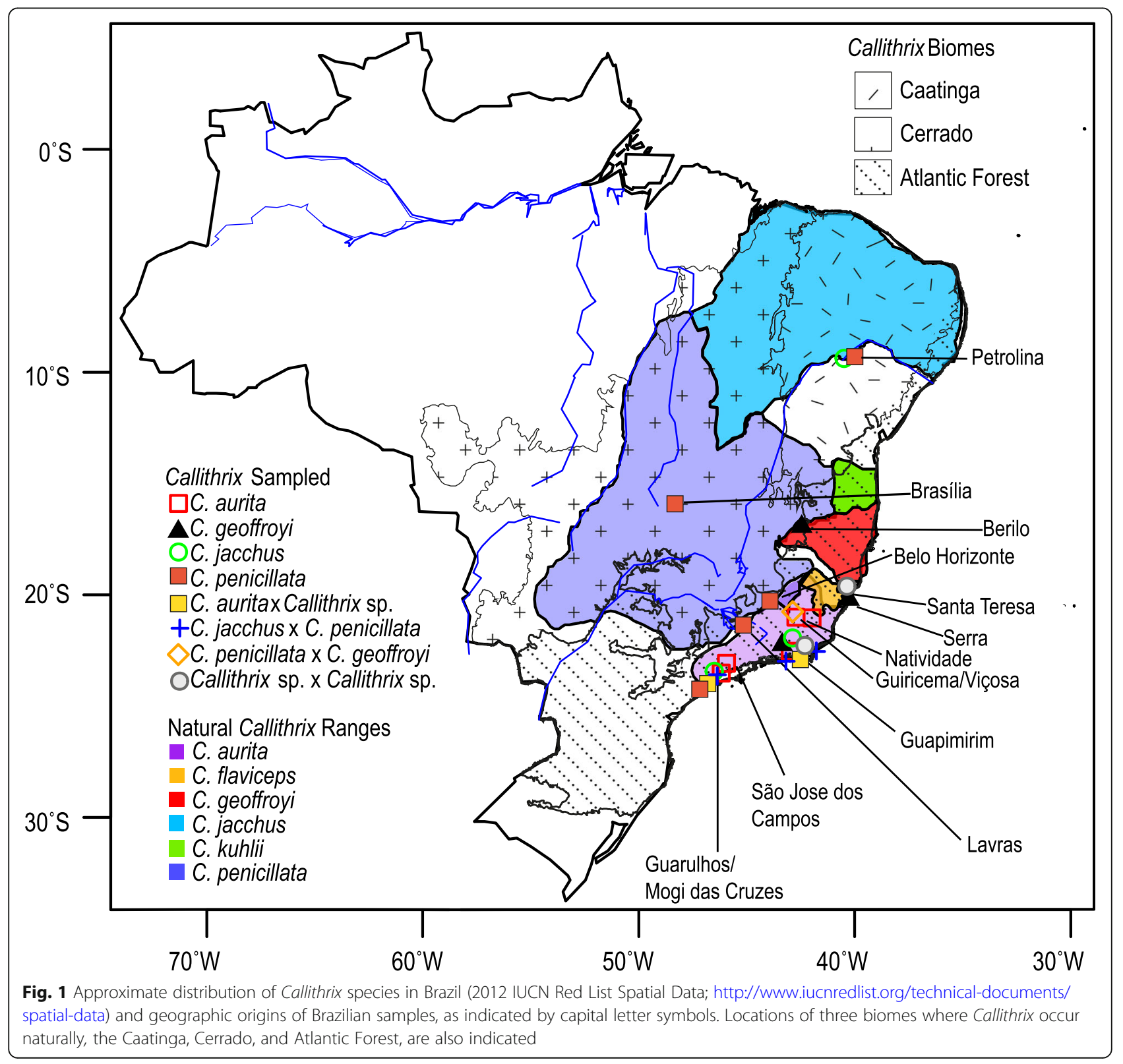


MtDNA sequence data can also provide initial genetic insight in the direction of introgression (if sex-biased) when two species hybridize due to incongruences between phenotypes and haplotypes (e.g., [14, 15]). The effective population size of mtDNA is one quarter of that of nuclear DNA from a diploid, bisexual population, which allows mtDNA lineages to coalescence relatively more quickly [17]. MtDNA is also considered a relatively fast mutating genetic marker [18]. As a result, lineage sorting and reciprocal monophyly are expected to occur faster in mtDNA than nuclear DNA, which can provide insight into shallow evolutionary relationships expected for young radiations.

One major challenge in applying genetic and genomic methods in Callithrix studies is an overall lack of genomic resources and sample material for most Callithrix species. Studies of Callithrix species have utilized mtDNA markers that generally resulted in polytomies and/or poorly supported branching patterns, as well as polyphyly for C. penicillata and C. kuhlii [19-23]. Also, the few available genetic studies of allochthonous and hybrid Callithrix within the Atlantic Forest, all conducted within Rio de Janeiro state, used portions of mtDNA or the Y-chromosome that could not fully resolve the evolutionary relationships of Callithrix lineages (e.g., [11, 23]). Nonetheless, [24] obtained a wellresolved phylogeny for the jacchus group using complete mitogenomes, but they only sampled one individual/species with unknown provenances.

To build upon the above previous Callithrix studies, we have conducted the largest to-date geographical sampling of Callithrix mitogenomes across Brazil (Fig. 1) with the following aims: (1) improve resolution of phylogenetic relationships and divergence times estimates between Callithrix mtDNA haplotypes; (2) determine which Callithrix mtDNA lineages are autochthonous across Callithrix ranges; and (3) identify allochthonous Callithrix mtDNA lineages in the southeastern Atlantic Forest and their possible biogeographic origins. We sequenced, for the first time, the complete mitogenome of C. aurita, and in total obtained 49 new mitogenome sequences from four species (C. aurita, C. geoffroyi, C. jacchus, C. penicillata), and four hybrid types (C. aurita $\mathrm{x}$ Callithrix sp., C. penicillata x C.jacchus, Callithrix sp. $\mathrm{x}$ Callithrix sp., C. penicillata x C. geoffroyi) for these analyses.

\section{Results}

Using Illumina whole genome sequencing (WGS) and Sanger sequencing approaches, we sequenced complete mitogenomes from 49 Callithrix (Fig. 1, Table 1, and Table S1). We combined these new mitogenomes with previously published primate mitogenome sequences for downstream analyses (listed in Table S1). The length of the resulting sequence alignment after combining all of these mitogenomes was 17,132 bases. Sampled individuals that possessed the same mtDNA haplotypes are listed in Table S2. The organization of the C. aurita mitogenome was consistent with previously published Callithrix mitogenomes from [24]. This mitogenome includes 12 protein-coding genes, two rRNAs, and 14 tRNAs on the heavy strand and one protein-coding gene and eight tRNAs on the light strand, as well as the control region (Table S3). The length of the C. aurita mitogenome presented in Table S3 was 16,471 bases.

\section{Phylogenetic trees and divergence times of Callithrix mitochondrial clades}

Maximum-likelihood (ML) and Bayesian inference produced well-supported phylogenetic trees that show mostly congruent phylogenetic relationships between the aurita and jacchus groups (Fig. 2, Figures S1-S3). The main difference in the topology of the ML and Bayesian trees was in grouping patterns of some haplotypes within the $C$. jacchus clade described below. A number of nodes in the ML tree possessed 100\% bootstrap support but most had bootstrap scores of $>70 \%$ (Figure S1). Most nodes in the Bayesian trees had posterior probabilities of 1 (Fig. 2, Figures S2-S3). Major node names and divergence times within and outside the Callithrix clade are shown in Fig. 2, Figure S3, Table 2, and Table S4.

Callithrix diverged from Cebuella approximately 6.83 Ma (Fig. 2 node E) and the initial split within Callithrix, separating $C$. aurita and the jacchus group, occurred approximately $3.54 \mathrm{Ma}$ (Fig. 2 node D) (Table 2). Thus, $C$. aurita formed the Callithrix basal clade, and C. geoffroyi formed the most basal clade within the jacchus group by arising $1.18 \mathrm{Ma}$ (node C). Callithrix penicillata haplotypes grouped into three polyphyletic clades that corresponded to three different biome regions, an Atlantic Forest-Cerrado transition area, Cerrado, and Caatinga. The first of these $C$. penicillata clades to diverge after $C$. geoffroyi was the Atlantic Forest-Cerrado transition clade at $0.92 \mathrm{Ma}$. Afterward, the $C$. penicillata Cerrado clade appeared at $0.87 \mathrm{Ma}$, followed by the $C$. kuhlii clade at $0.82 \mathrm{Ma}$ (Fig. 2 node B). The C. penicillata Caatinga clade and the $C$. jacchus clades represent the two youngest clades within the phylogeny, splitting about $0.51 \mathrm{Ma}$ (Fig. 2 node A). As the C. jacchus clade showed some of the shallowest branch tips among Callithrix haplotypes and poor phylogenetic resolution, a ParsimonySplits network was constructed for haplotypes within this clade (Fig. 3).

\section{Ancestral origins and biogeography of Callithrix Mitogenomes}

The ancestral origins of Callithrix phylogenetic mitogenome clades and subclades based on BMM biogeographic 
Table 1 Number of Callithrix specimens newly sampled by species and hybrid phenotype

\begin{tabular}{|c|c|c|c|}
\hline Phenotype & Provenance & Approximate Geographic Coordinates & $\mathbf{N}$ \\
\hline C. aurita & Guiricema, Minas Gerais, Brazil & $-21.0081075,-42.7231066$ & 2 \\
\hline C. aurita & $\begin{array}{l}\text { Guarulhos Municipal Zoo, Guarulhos, São Paulo, Brazil (wild } \\
\text { marmoset originally from Mogi das Cruzes, São Paulo) }\end{array}$ & $-23.5391655,-46.1960017$ & 1 \\
\hline C. aurita & Guarulhos Municipal Zoo, Guarulhos, São Paulo, Brazil & $-23.4425682,-46.5535750$ & 2 \\
\hline C. aurita & $\begin{array}{l}\text { Guarulhos Municipal Zoo, Guarulhos, São Paulo, Brazil (wild } \\
\text { marmoset originally from São José dos Campos, São Paulo) }\end{array}$ & $-23.1701146,-45.8938482$ & 1 \\
\hline C. aurita & $\begin{array}{l}\text { CPRJ, Guapimirim, Rio de Janeiro, Brazil (wild marmosets } \\
\text { originally from Natividade, Rio de Janeiro) }\end{array}$ & $-21.0605955,-41.9771042$ & 2 \\
\hline C. aurita & CPRJ, Guapimirim, Rio de Janeiro, Brazil & $-22.4885811,-42.9136052$ & 1 \\
\hline C. geoffroyi & Callitrichid Research Center, Omaha, Nebraska, US & $-41.2549350,-95.9768850$ & 1 \\
\hline C. geoffroyi & CPRJ, Guapimirim, Rio de Janeiro, Brazil & $-22.4885811,-42.9136052$ & 1 \\
\hline C. geoffroyi & Berilo, Minas Gerais, Brazil & $-16.9307333,-42.4849902$ & 1 \\
\hline C. geoffroyi & Serra, Espírito Santo, Brazil & $-20.1903636,-40.2374422$ & 3 \\
\hline C. jacchus & Guarulhos Municipal Zoo, Guarulhos, São Paulo, Brazil & $-23.4425682,-46.5535750$ & 2 \\
\hline C. jacchus & NEPRC, Southborough, Massachusetts, US & $42.2996480,-71.5358183$ & 1 \\
\hline C. jacchus & CEMAFAUNA, Petrolina, Pernambuco, Brazil & $-9.3272051,-40.5441172$ & 4 \\
\hline C. jacchus & CPRJ, Guapimirim, Rio de Janeiro, Brazil & $-22.4885811,-42.9136052$ & 1 \\
\hline C. penicillata & Brasília, Federal District, Brazil & $-15.8014526,-47.9234345$ & 2 \\
\hline C. penicillata & Lavras, Minas Gerais, Brazil & $-21.2292301,-44.9988343$ & 2 \\
\hline C. penicillata & Belo Horizonte, Minas Gerais, Brazil & $-19.8703102,-43.9696589$ & 2 \\
\hline C. penicillata & CEMAFAUNA, Petrolina, Pernambuco, Brazil & $-9.3272051,-40.5441172$ & 2 \\
\hline C. jacchus $\times$ C. penicillata & CPRJ, Guapimirim, Rio de Janeiro, Brazil & $-22.4885811,-42.9136052$ & $1(\mathrm{P})$ \\
\hline C. penicillata $\times$ C. geoffroyi & Viçosa, Minas Gerais, Brazil & $-20.7639782,-42.8990971$ & 11 (all P) \\
\hline C. aurita $\times$ Callithrix sp. & Guarulhos Municipal Zoo, Guarulhos, São Paulo, Brazil & $-23.4425682,-46.5535750$ & $3(J, G, P)$ \\
\hline C. aurita $\times$ Callithrix sp. & $\begin{array}{l}\text { Guarulhos Municipal Zoo, Guarulhos, São Paulo, Brazil (wild } \\
\text { marmoset originally from Maripora, São Paulo) }\end{array}$ & $-23.3412818,-46.5754474$ & $1(J)$ \\
\hline C. aurita $\times$ Callithrix sp. & CPRJ, Guapimirim, Rio de Janeiro, Brazil & $-22.4885811,-42.9136052$ & $1(\mathrm{~A})$ \\
\hline C. geoffroyi x Callithrix sp. & Santa Teresa, Espírito Santo, Brazil & $-19.9394185,-40.6009700$ & $1(\mathrm{G})$ \\
\hline Total & & & 49 \\
\hline
\end{tabular}

Provenance abbreviations are: CRC Callitrichid Research Center, NEPRC New England Primate Research Center (no longer in operation), CPRJ Centro de Primatologia do Rio de Janeiro, and CEMAFAUNA Centro de Conservação e Manejo de Fauna da Caatinga. Letters in parentheses next to numerical values listed in the " $\mathrm{N}$ " column for hybrid marmosets correspond to likely maternal species of each hybrid based on phylogenetic analyses presented in Figs. 2, and S1-S3. Maternal species abbreviations are- A: C. aurita, G: C. geoffroyi, J: C. jacchus; and P: C. penicillata

analysis were largely concordant with the assigned Brazilian states and regions of origin of sampled mitogenomic haplotypes (Fig. 4 and Table S5). BMM analyses resulted in $>70 \%$ posterior probability of an ancestral origin for Node 93, which represented the basal node of the $C$. aurita clade, in Rio de Janeiro state. Within the C. aurita clade, node 92 showed $>97 \%$ posterior probability of an ancestral original of Rio de Janeiro state for two haplotypes sampled within this region from $C$. aurita-phenotype individuals and a $C$. aurita $\mathrm{x}$ Callithrix sp. hybrid. On the other hand, BMM analysis for nodes 89-91, which represent the other C. aurita subclade, assigned posterior probabilities between 44 and $65 \%$ for an origin of the Minas Gerais state portion of the natural C. aurita range. These haplotypes were obtained from $C$. aurita-phenotype individuals sampled in Minas Gerais,
São Paulo, and Rio de Janeiro states, as well as a C. aurita x Callithrix sp. hybrid from São Paulo state.

Node 87 in Fig. 4 represents the basal node of the C. geoffroyi clade, and BMM analyses calculated a collective posterior probability of over $75 \%$ of this clade originating within the natural range of $C$. geoffroyi. With a BMM posterior probability of $91.93 \%$ that node 85 originated in southeastern Espírito Santo state, biogeographic analysis accurately reflected the sampling origin of haplotypes BJT70 and BJT169. These haplotypes come from $C$. geoffroyi-phenotype individuals, as well as one Callithrix sp. x Callithrix $s p$. hybrid. For the other C. geoffroyi subclade, BMM analyses posterior probabilities support an ancestral origin of associated haplotypes within the natural distribution of C. geoffroyi. 


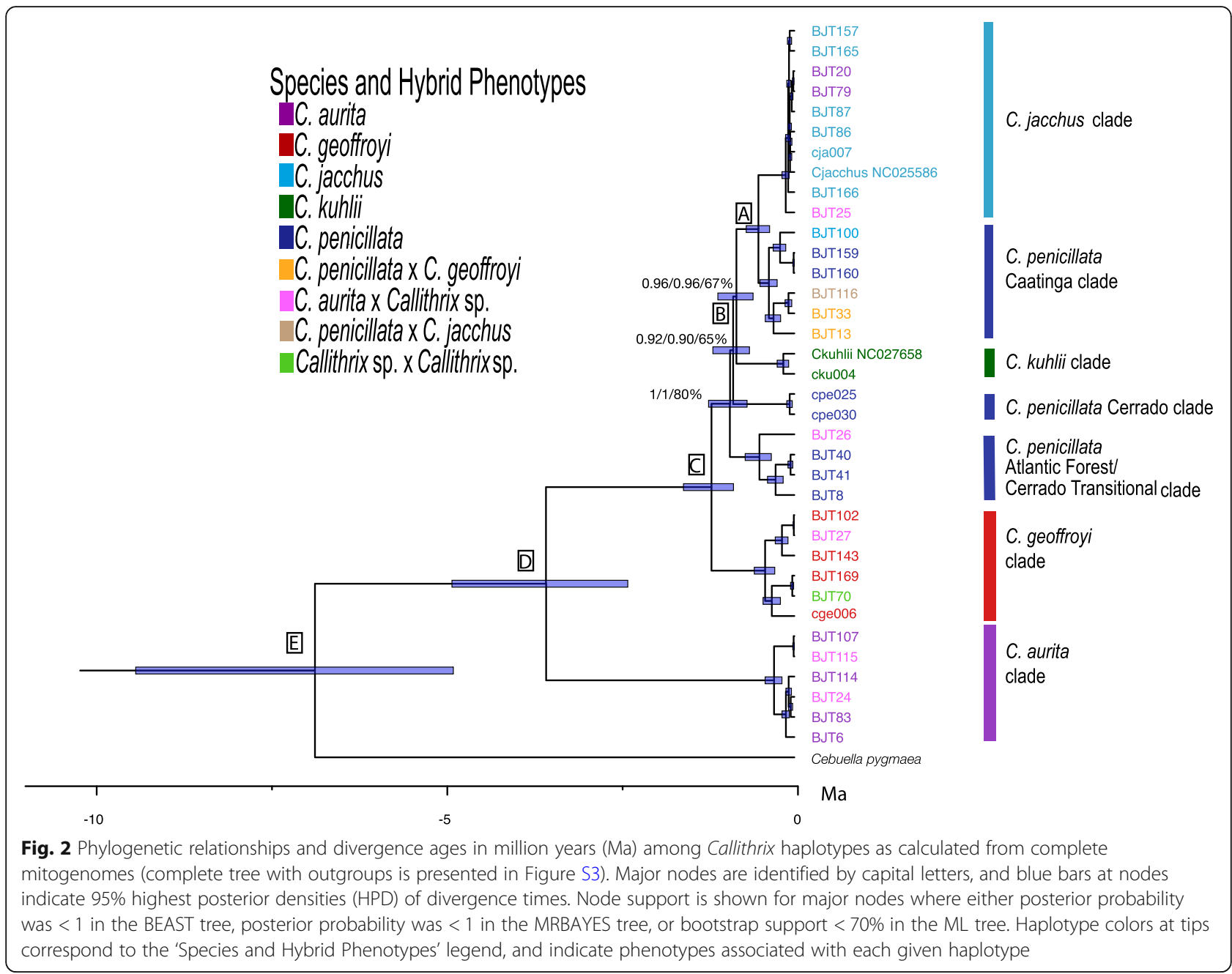

For the three C. penicillata clades, BMM analysis showed high posterior probabilities for each clade's corresponding geographic area as also being each respective clade's ancestral region. Nodes 79-81 (Fig. 4), which represent the $C$. penicillata Atlantic Forest-Cerrado transition clade, each possessed $>98 \%$ posterior probabilities of originating in the Atlantic Forest-Cerrado transition zone of Minas Gerais. This clade contained several haplotypes from C. penicillata-phenotype individuals sampled in this transition zone, as well as a hybrid sampled in São Paulo state. The BMM posterior probability for the central Brazil
Cerrado being the ancestral region for node 77 (Fig. 4), which encompassed the $C$. penicillata Cerrado clade, was 98.16\%. The C. penicillata Cerrado clade included haplotypes from $C$. penicillata-phenotype individuals sampled in Brasília. Finally, nodes 69-73 (Fig. 4), representing the C. penicillata Caatinga clade, possessed BMM posterior probability support between $96.14-99.60 \%$ for the Caatinga of Bahia state as the ancestral region of this clade. The clade contained haplotypes from C. penicillataphenotype animals sampled at CEMAFAUNA, which clustered with a haplotype from a $C$. penicillata $\mathrm{x} C$.

Table 2 Divergence times in million years (Ma) for Callithrix species and select nodes (MRCA = Most recent common ancestor; values in brackets $=95 \%$ highest posterior density). Node names follow major node destinations shown in Fig. 2 in capital letters

\begin{tabular}{llr}
\hline Node & Taxa Diverging at Node & Age (Ma) \\
\hline A & C. jacchus - C. penicillata (Caatinga clade) & $0.51[0.35-0.69]$ \\
B & C. kuhlii - (C. jacchus + C. penicillata (Caatinga clade)) & $0.82[0.59-1.09]$ \\
C & C. geoffroyi - (C. kuhlii + (C. jacchus + C. penicillata)) & 1.18 [0.87-1.58] \\
D & C. aurita - (C. geoffroyi + (C. kuhlii + (C. jacchus + C. penicillata))) & $3.54[2.37-4.88]$ \\
E & Callithrix - Cebuella/Mico & $6.83[4.86-9.39]$ \\
\hline
\end{tabular}




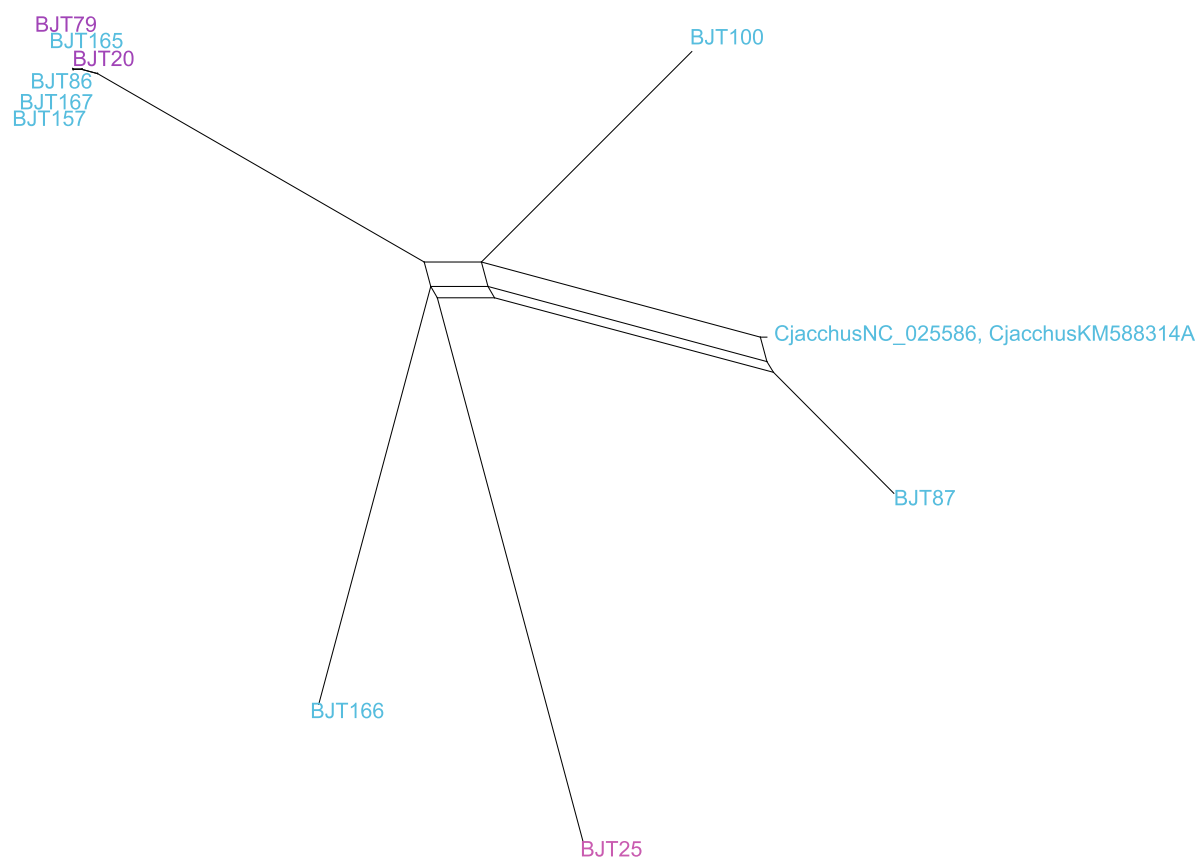

Fig. 3 ParimonySplits network of haplotypes from phylogenetic C. jacchus clade. Haplotype colors at tips follow Fig. 1 'Species and Hybrid Phenotypes' legend, and indicate phenotypes associated with each given haplotype

jacchus hybrid with a C. jacchus phenotype sampled at CPRJ. Two haplotypes, representing eleven C. penicillata $\mathrm{x}$ C. geoffroyi hybrids sampled in Viçosa as well as a C. jacchus x C. penicillata hybrid, clustered within the C. penicillata Caatinga group.

BMM biogeographic analysis of the C. jacchus clade calculated high posterior probability (>99\%) that haplotypes associated with nodes 60-64 originated in Ceará and/or Pernambuco states, regions whose dominant biome is the Caatinga. These haplotypes were obtained from marmosets with $C$. jacchus phenotypes sampled at CEMAFAUNA and the Guarulhos Zoo, as well as three C. aurita phenotype individuals sampled within São Paulo. For nodes 65-68, BMM analyses calculated posterior probabilities of the associated haplotypes originating first from Pernambuco, and then from Ceará and/or Pernambuco. In particular, nodes 66 and 67 had respective posterior probabilities of 49.68 and $76.88 \%$ of originating in Pernambuco state. Haplotypes associated with these nodes came from a C. aurita x Callithrix sp. hybrid sampled in São Paulo state and a CEMAFAUNA $C$. jacchus-phenotype individual.

\section{Genetic distance between Callithrix phylogenetic clades}

Pairwise genetic distances between the above established phylogenetic clades are shown in Table 3 as measures of $\mathrm{D}_{\mathrm{xy}}$. The $C$. aurita clade was the most genetically distant from all other Callithrix clades, with $\mathrm{D}_{\mathrm{xy}}=0.055-0.056$. The smallest genetic distance can be observed between C. jacchus and the C. penicillata Caatinga clade at $\mathrm{D}_{\mathrm{xy}}=$ 0.009 . The remaining pairwise genetic distances varied between $\mathrm{D}_{\mathrm{xy}}=0.013-0.015$, but the $C$. geoffroyi clade was the most distant relative to all other jacchus group clades.

\section{Discussion}

Callithrix mitochondrial phylogenetic relationships and divergence times

Our ML and Bayesian phylogenies were generally well supported and corroborated Callithrix divergence patterns from previous nuclear and mtDNA studies [3, 2426]. In ours and these previous phylogenies, the $C$. aurita clade was the most basal within the genus, the $C$. geoffroyi clade was most basal within the jacchus group, and C. penicillata and C. jacchus was the most recently diverged sister clade. Finally, our mtDNA analysis also showed that $C$. penicillata mitochondrial clades are polyphyletic, similar to the results obtained by [21, 23] The latter two studies also showed that C. kuhlii mitochondrial clades are polyphyletic. Given the recent divergence times of Callithrix species, Callithrix polyphyly may be explained by incomplete lineage sorting when ancestral polymorphisms at a given locus are not fixed before population divergence [27]. Another possibility to 


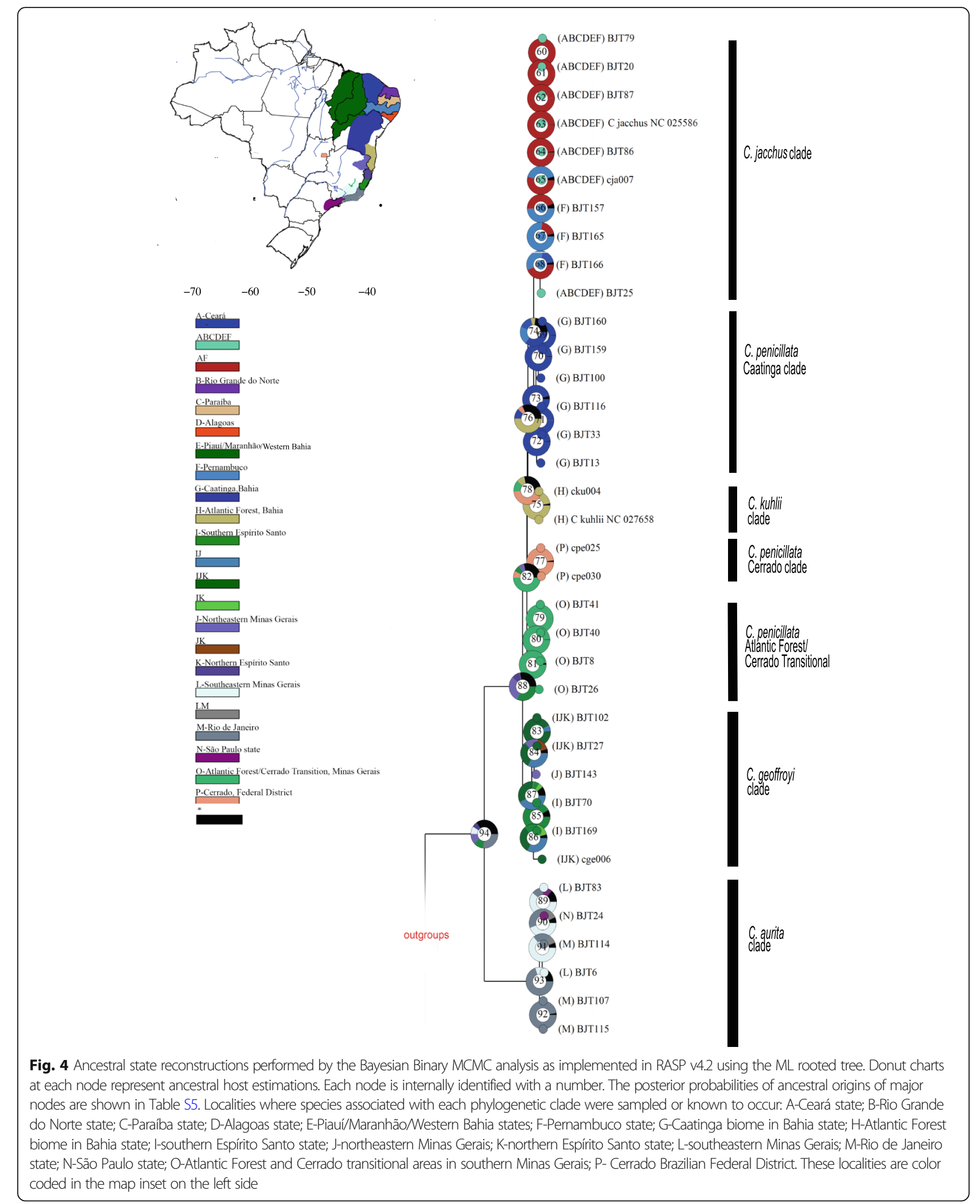


Table 3 Array of pairwise $D_{x y}$ genetic distances between Callithrix phylogenetic clades

\begin{tabular}{|c|c|c|c|c|c|c|}
\hline & $\begin{array}{l}\text { C. } \\
\text { jacchus }\end{array}$ & & & & & \\
\hline C. penicillata (Caatinga clade) & 0.009 & $\begin{array}{l}\text { C. penicillata } \\
\text { (Caatinga clade) }\end{array}$ & & & & \\
\hline C. kuhlii & 0.014 & 0.013 & $\begin{array}{l}\text { C. } \\
\text { kuhlii }\end{array}$ & & & \\
\hline C. penicillata (Cerrado clade) & 0.016 & 0.015 & 0.014 & $\begin{array}{l}\text { C. penicillata } \\
\text { (Cerrado clade) }\end{array}$ & & \\
\hline $\begin{array}{l}\text { C. penicillata (Atlantic Forest/ Cerrado } \\
\text { Transitional clade) }\end{array}$ & 0.015 & 0.016 & 0.014 & 0.015 & $\begin{array}{l}\text { C. penicillata (Atlantic Forest/ Cerrado } \\
\text { Transitional clade) }\end{array}$ & \\
\hline C. geoffroyi & 0.018 & 0.017 & 0.017 & 0.018 & 0.017 & $\begin{array}{l}\text { C. } \\
\text { geoffroyi }\end{array}$ \\
\hline C. aurita & 0.056 & 0.056 & 0.055 & 0.056 & 0.055 & 0.056 \\
\hline
\end{tabular}

explain $C$. penicillata and $C$. kuhlii polyphyly may be due to past hybridization between these species and other Callithrix taxa or perhaps recent migrations of $C$. kuhlii outside of its native range. However, we do not believe is likely for any of these cases. For these alternative scenarios, we would expect to find at least some instances of allochthonous C. kuhlii mtDNA lineages, which to our knowledge have not been yet been reported. Additionally, we did not observe any discordance involving of C. kuhlii genotype/phenotype with that of any other Callithrix species, nor did mitogenome haplotypes from any hybrids sampled in this or previous studies group with C. kuhlii phylogenetic clades. Finally, locations where we sampled Callithrix species within native ranges were far removed from any natural hybridization zones with $C$. kuhlii, so natural secondary contact between $C$. kuhlii and other Callithrix species was unlikely at our sampling locations. Thus, incomplete lineage sorting is the most parsimonious explanation for Callithrix polyphyly observed in this and previous Callithrix studies.

The Callithrix divergence time estimates from our study, being between approximately 0.5 and $6.8 \mathrm{Ma}$, are within the range of previously published estimates [6, $25,26]$. These time estimates place the divergence of Callithrix species into the Pleistocene. In this epoch, climatic oscillations that may have promoted para- and allopatric speciation in South America, including that of Callithrix species, through repeated contractions and expansions of forested refuge [28, 29].

\section{Biogeography origins of autochthonous and Allochthonous Callithrix Mitogenomes}

Previous phylogenetic and biogeographic analyses support a Callithrix origin in the southeastern Brazilian Atlantic Forest and then a northward expansion [3, 4, 2426]. Our biogeographic analysis of Callithrix mitogenome lineages reflected similar biogeographic patterns for Callithrix species, as well as a natural geographic separation of major phylogenetic clades. When considering sampled mitogenome lineages of known provenance, the biogeographic origins of our reconstructed phylogenetic clades was strongly influenced by the geographic origin of our samples across natural Callithrix ranges. For example, within the $C$. geoffroyi clade, the Minas Gerais state lineage formed a separate clade from the Espírito Santo state lineages. Callithrix penicillata possesses the largest natural geographic distribution of all Callithrix species [5] and biogeographic origins of paraphyletic clades were defined by where samples were collected within the Cerrado, Atlantic Forest, and Caatinga biomes. Although most sampled C. jacchus clade haplotypes did not possess known provenance and showed shallow tips, biogeographic analyses showed strong evidence that these haplotypes likely originated from within the Caatinga biome. Further evidence that C. jacchus mtDNA lineages tend to group geographically under denser sampling was shown by [23] with a geographically broader sampling of $C$. jacchus mtDNA D-loop sequences. We did observe a single haplotype from an individual with a $C$. jacchus phenotype group within the C. penicillata Caatinga clade. This individual represents a cryptic hybrid $C$. penicillata $\mathrm{x} C$. jacchus that was sampled in captivity at CPRJ. Since this hybrid was sampled in southeastern Brazil, far removed from any of the natural C. penicillata x C. jacchus hybrid zones that occur in northeastern Brazil [6], this marmoset is likely an anthropogenic hybrid.

Allochthonous Callithrix species began appearing in portions of the southeastern Brazilian Atlantic Forest within approximately the last $20-30$ years $([30,31]$, pers. obs. C. Igayara). Our biogeographic analyses can be used to infer the probable origins of parental populations of these allochthonous Callithrix species and anthropogenic hybrid Callithrix found in the southeastern Brazilian Atlantic Forest. Overall, biogeographic patterns show that the parental populations of these Callithrix likely possess multiple geographic origins from within and 
outside Atlantic Forest. For example, our biogeographic results show that mtDNA haplotypes of three $C$. aurita $\mathrm{x}$ Callithrix sp. hybrids we sampled in São Paulo state respectively originated from northeastern Minas Gerais or Espírito Santo states, the Atlantic Forest-Cerrado Transitional region, and the Caatinga. On the other hand, the likely provenance of a haplotype of $C$. aurita $\mathrm{x}$ Callithrix sp. individual was Guapimirim, Rio de Janeiro state. The three haplotypes from C. penicillata x C. geoffroyi hybrids we sampled in Minas Gerais state and a $C$. jacchus x C. penicillata hybrid sampled from Rio de Janeiro state likely originated from the Caatinga.

\section{Implications of biological invasions for Callithrix genetic integrity, hybridization, and conservation}

Several species of non-native fauna and flora have been introduced to the Brazilian Atlantic Forest [32] - one of the most anthropogenically disturbed, yet highly biodiverse biomes on Earth [33, 34]. Deliberate and accidental relocations of species beyond their natural geographic ranges by humans may lead to the establishment of nonautochthonous populations and biological invasions within new geographic localities. Such introductions alter the ecological relationships among taxa, and in cases of closely related species, gene flow may occur due to hybridization [35-37].

Indeed, our analyses show, for the first time, evidence of introgression of genetic material from allochthonous $\mathrm{Cal}$ lithrix species into the genetic background of an endangered, autochthonous Callithrix species. Two mtDNA haplotypes that grouped within the $C$. jacchus clade were associated with three individuals with pure $C$. aurita phenotypes sampled within São Paulo state. Two of these individuals were sampled in two different regions of São Paulo state in municipalities (Mogi Das Cruzes and São José dos Campos) that lie $60 \mathrm{~km}$ apart. These data not only show the first genetic evidence for cryptic hybridization within the aurita group marmosets, but also suggest two independent occurrences of a $C$. jacchus female mating with a $C$. aurita male that led to genetic introgression. Under scenarios of biological invasions, theoretical and empirical data show that hybridization between allochthonous species and endangered, native species creates extinction risk for the latter [38]. Our initial mtDNA data strongly prompt for the development of diagnostic genetic markers to detect the actual extent of allochthonous Callithrix genetic introgression in C. aurita populations, particularly within São Paulo state.

Contemporary anthropogenic hybrid Callithrix and allochthonous Callithrix species are normally found in urban or peri-urban areas of southeastern Brazil, due to releases of exotic pet marmosets into such locales [6, 9, 10, 31], where they may encounter autochthonous Callithrix species. Indeed, cases exist of native $C$. aurita and
C. flaviceps meeting up and interbreeding with hybrid and allochthonous Callithrix at urban fringes [6,9-11, 39, 40]. Such interactions likely facilitate gene flow from invasive $C$. jacchus and $C$. penicillata into marmoset populations in southeastern Brazil, with consequences that may include outbreeding depression, admixture, hybrid swamping, or introgressive replacement [41-44].

Invasive $C$. jacchus and C. penicillata represent a potential risk for genetic extinction of the other two jacchus group species, C. geoffroyi and C. kuhlii, and [10] recently showed that $C$. penicillata is encroaching on the range of C. geoffroyi. We sampled one Callithrix sp. $\mathrm{x}$ Callithrix sp. hybrid in Santa Teresa, Espírito Santo state, a city that straddles the native ranges of $C$. flaviceps and C. geoffroyi. Although this hybrid possessed a C. geoffroyi clade mitogenome lineage, the individual had a phenotype that strongly suggested some level of $C$. penicillata or $C$. jacchus ancestry- a white "star" on the forehead [30]. Anthropogenic hybridization of jacchus group species generally results in the formation of hybrid swarms, admixed populations that lost parental phenotypes and genotypes [2, 6, 30]. Should large numbers of exotic $C$. jacchus or C. penicillata ever invade native ranges of $C$. kuhlii or C. geoffroyi, the latter two species may be threatened with genetic swamping by the former two species, a process through which parental lineages are replaced by hybrids that have admixed genetic ancestry [38]. As C. kuhlii is considered vulnerable [45], biological invasions by other marmosets present potential conservation risks for this species.

Brazil already possesses several legal instruments for the conservation and protection of wildlife (discussed in [46]). These instruments include national species plans that legally lay out and action plans for the protection of specific groups of endangered species. A national species plan already exists that includes C. aurita and C. flaviceps, the National Action Plan for the Conservation of Atlantic Forest Primates and Collared Sloth (PAN PPMA, [46]), and this plan may eventually need to include $C$. kuhlii. The PAN PPMA considers hybridization as a major threat to the survival of the aurita group marmoset species. Thus, the expanded perspective on marmoset hybridization provided by this work should be considered within the context of Brazilian legal instruments that protect endangered marmosets. Such an evaluation is important for incorporating new biological information about marmoset hybridization, as it may call for adopting new legal measures or modifying existing ones to further protect endangered Brazilian fauna.

\section{Conclusions}

We provide a robust Callithrix phylogeny based on the largest to-date geographical sampling of Callithrix mitogenomes across Brazil, showing that the aurita group is 
basal to the jacchus group. Our divergence time estimates show these two groups diverged approximately $3.54 \mathrm{Ma}$, and within the jacchus group, $C$. jacchus diverged most recently from the $C$. penicillata Caatinga clade approximately $0.51 \mathrm{Ma}$. With future sampling of $C$. flaviceps, full mitogenomes can likely be utilized to fully resolve the Callithrix phylogeny. Nonetheless, we used our current wellsupported phylogenies and biogeographic analyses to elucidate, for the first time, evolutionary relationships among autochthonous, allochthonous, and anthropogenic hybrid marmosets across Brazil. We show that parental populations of allochthonous and anthropogenic hybrid marmosets within the southeastern Brazilian Atlantic Forest incorporate local populations and populations broadly distributed outside of the regions. We also show, for the first time, evidence of allochthonous Callithrix species genetic introgression into the genetic background of endangered, autochthonous $C$. aurita. At this time, further determination is needed of the ancestry of Callithrix anthropogenic hybrids in southeastern Brazil as well as the fitness and viability of these hybrids. Such data will help determine to what extent anthropogenic hybrids and allochthonous Callithrix species threaten the genetic integrity, or ability of a population to preserve its genotypes over generations [47], of autochthonous Atlantic Forest Callithrix species.

\section{Methods}

\section{Samples}

In 2011, skin samples were collected from two C. penicillata individuals that were captured in Brasília, Federal District. Between 2010 and 2016, skin tissue was collected from: (1) wild marmosets in Minas Gerais and Espírito Santo states as well as the Brazilian Federal District; (2) captive-born, wild-caught, and confiscated marmosets housed at the Guarulhos Municipal Zoo, Guarulhos, São Paulo, CEMAFAUNA (Centro de Manejo de Fauna da Caatinga), Petrolina, Pernambuco, and Centro de Primatologia do Rio de Janeiro (CPRJ), Guapimirim, Rio de Janeiro; (3) a wild group from Natividade, Rio de Janeiro that was caught and housed at CPRJ; (4) a captive-born C. geoffroyi sample donated by the Callitrichid Research Center (CRC), Omaha, Nebraska, US; (5) a captive born $C$. jacchus donated by the New England Primate Research Center (NEPRC, now closed), Southborough, Massachusetts, US. Sampling consisted of a total of 49 Callithrix individuals as described in Table 1, Table S1, and Fig. 1. Table S1 also lists information on utilized sequences that were published elsewhere. Marmoset capture and sampling methodology has been described elsewhere [23]. All individuals were allowed to recover after sample collection, and wild marmosets were released at their point of capture. Specimens were classified phenotypically as pure C. aurita, $C$. geoffroyi, C. jacchus and C. penicillata or hybrid (C. aurita x Callithrix sp., C. jacchus $\mathrm{x}$ C. penicillata, and $C$. penicillata $\mathrm{x}$ C. geoffroyi) based on published descriptions [2, 11, 23, 30].

\section{Laboratory protocols}

DNA from skin samples was extracted using a standard proteinase $\mathrm{K} / \mathrm{phenol} / \mathrm{chloroform}$ protocol [48]. Buffers used for extraction, precipitation and elution of DNA from blood and skin tissue are listed elsewhere [24]. DNA from the Callitrichid Research Center samples was extracted at Arizona State University (ASU). DNA from Brasília individuals was extracted at Northern State Fluminense University, Rio de Janeiro State, Brazil, and then exported to ASU (CITES permit \#11BR007015/DF). DNA from all other individuals was extracted at the Federal University of Viçosa (UFV), Viçosa, Minas Gerais, Brazil.

Mitogenomes were obtained for a subset of the samples (Table S1) following the long-range PCR (LR-PCR) methodology of [24], and sequenced on an ABI 3730 sequencer with the BigDye Cycle Sequencing Kit (Applied Biosystems) by the ASU School of Life Science DNA Core Laboratory. The remainder of mitogenomes was obtained from whole genome sequencing (WGS). Individual WGS sequencing libraries were prepared at UFV and ASU with Illumina Nextera DNA Flex Library Prep Kits (catalog \#20018704) following manufacturer's instructions. Individual libraries were barcoded with Illumina Nextera DNA CD Indexes (catalog \# 20018707), and pooled in equimolar amounts and sequenced on an Illumina NextSeq using v2 chemistry for $2 \times 150$ cycles at the ASU Genomic Core Facilities.

\section{Mitogenome alignment and data analysis}

Genetic samples collected since 2015 have been registered in the Brazilian CGen SISGEN database (Supplementary Table S6) and newly sequenced mitogenomes have been deposited in GenBank (Table S1). Trace files of resulting forward and reverse reads from LR-PCR products for each individual sequence were inspected by eye and merged into a single contig for each sampled individual using SEQMAN PRO software from the DNAStar Lasergene Core 10 suite (DNASTAR, Madison, WI). Mitogenomes from WGS data were assembled with NOVOPlasty 2.6.4 [49] (scripts available at https:// github.com/Callithrix-omics/Callithrix_mtDNA.git). We downloaded mitogenome sequences of several primate species from GenBank (Supporting Information Table S1). All mitogenomes were aligned in MAAFT (https:// www.ebi.ac.uk/Tools/msa/mafft/) with default settings and this MAFFT alignment was confirmed visually in Mesquite 3.5 [50]. Gene, tRNA, rRNA, and control region features within the newly generated marmoset mitogenomes were manually annotated based on the 
GenBank record of C. kuhlii (Accession number KR817257). To check for the presence of nuclear mitochondrial DNA (numts) in mitochondrial sequence data, we followed the strategy described in [24].

We kept mitogenomes in their entirety, but trimmed part of tRNA-Phe, $12 \mathrm{~s}$ rRNA and the control region to accommodate the length of all utilized sequences. Mitogenome haplotypes were determined with DnaSP 6.12.03 [51], and haplotypes were used for phylogenetic reconstruction. Individuals that possess identical mtDNA haplotypes are listed in Table S3, and these groups are represented in phylogenetic reconstructions by a single haplotype. We added data from several other New World monkeys (Table S1) and reconstructed phylogenetic trees with ML and Bayesian algorithms using IQTREE 2.0.3 [52] and MrBayes 3.2.6 [53, 54], respectively. For the ML phylogeny, we used the optimal substitution model $(\mathrm{GTR}+\mathrm{F}+\mathrm{R} 4)$ as calculated with ModelFinder $[55,56]$ in IQ-TREE under the Bayesian Information Criterion (BIC). We performed the ML analysis in IQTREE with 10,000 ultrafast bootstrap (BS) replications [57]. In MrBayes, we used the closest available substitution model GTR + G. The Bayesian tree was reconstructed via Markov Chain Monte Carlo (MCMC) runs with 10,000,000 generations and tree and parameter sampling occurring every 100 generations. Upon completion of the two runs, the first $25 \%$ of generations were discarded as burn-in. To check convergence of all parameters and the adequacy of the burn-in, we assessed the uncorrected potential scale reduction factor (PSRF) [58] and that all parameter Estimated Sample Size (ESS) values were above 200 . We calculated posterior probabilities (PP) and a phylogram with mean branch lengths from the posterior density of trees using MrBayes. Phylogenetic trees were visualized and edited with FigTree 1.4.2 (http://tree.bio.ed.ac.uk/software/figtree/). Pairwise genetic distances between each of the resulting Callithrix mitochondrial clades was measured in DnaSP 6.12 .03 as $D_{x y}$, the average number of per site nucleotide substitutions between clades.

The divergence time calculation was performed with the BEAST 2.4.8 package [59] using a relaxed lognormal clock model of lineage variation [60] and by applying a Yule tree prior and the best-fit model of sequence evolution as obtained by ModelFinder. To calibrate the molecular clock, we applied fossil data to constrain the splits between Cebinae and Saimirinae and between Callicebinae and Pitheciinae with hard minimum and soft maximum bounds using a log normal prior following settings and fossils described in detail in [61]. Briefly, for the Cebinae - Saimirinae split, we used an offset of 12.6, mean of 1.287 and standard deviation of 0.8 , which translates into a median divergence of 16.2 million years ago (Ma) (95\% highest posterior density [HPD]: 13.4-
30.0 Ma). For the Callicebinae - Pitheciinae split, we used an offset of 15.7, mean of 1.016 and standard deviation of 0.8 , resulting in a median divergence of $18.5 \mathrm{Ma}$ (95\% HPD: 16.3-28.9 Ma). We performed two independent runs each with 50 million generations and tree and parameter sampling setting in every 5000 generations. To assess the adequacy of a $10 \%$ burn-in and convergence of all parameters, we inspected the trace of the parameters across generations using Tracer 1.6 [62]. We combined sampling distributions of both replicates with LogCombiner 2.4.8 and summarized trees with a $10 \%$ burn-in using TreeAnnotator 2.4.8 (both programs are part of the BEAST package). A ParimonySplits network of a subset of mtDNA haplotypes was made with default settings in SplitsTree4 [63].

To reconstruct the biogeographic history of Callithrix mitochondrial lineages, we applied the Bayesian Binary Method (BBM) in Reconstruct-Ancestral-States-in-Phylogenies 4.0 (RASP) $[64,65]$. The ML phylogeny obtained with IQTREE was used for the BBM analysis, which was conducted as two independent runs of 10 chains that ran for 5,000,000 generations and sampled every 100 generations. The fixed Jukes-Cantor+Gamma evolutionary model was implemented for each run. For haplotypes states of origin within a given phylogenetic clade, presence and absence of each associated taxon was determined using a combination of information of known provenance for sampled individuals and recognized Callithrix geographical distribution following [5]. For haplotypes obtained from exotic Callithrix species and anthropogenic hybrids, we noted where each of these haplotypes clustered among resulting phylogenetic clades, and assigned probable origin for these haplotypes according to the likely natural geographic range associated with each clade.

\section{Abbreviations}

ASU: Arizona State University; BBM: Bayesian Binary Method; BIC: Bayesian Information Criterion; BS: Bootstrap; CEMAFAUNA: Centro de Conservação e Manejo de Fauna da Caatinga; CPRJ: Centro de Primatologia do Rio de Janeiro; CRC: Callitrichid Research Center; ESS: Estimated Sample Size; HPD: Highest posterior density; LR-PCR: long-range PCR;

mtDNA: mitochondrial DNA; Ma: million years ago; MCMC: Markov Chain Monte Carlo; MRCA: Most recent common ancestor; ML: Maximum likelihood; NEPRC: New England Primate Research Center; PP: Posterior probabilities; PSRF: potential scale reduction factor; UFV: Universidade Federal de Viçosa; WGS: Whole genome sequencing

\section{Supplementary Information}

The online version contains supplementary material available at https://doi. org/10.1186/s12864-021-07533-1.

Additional file 1: Table S1. Metadata for newly collected samples as well as primate mitogenome sequences obtained from GenBank. The 'Sample' column gives ID of each new sampled individual or the species for sequences obtained from previous studies. The 'Accession' column gives GenBank accession numbers for each sequence, the 'Assembly Method This Study' column states the manner in which new Callithrix 
mitogenomes were sequenced and assembled ( $\mathrm{S}=\mathrm{Sanger} ; \mathrm{N}=$ NOVOPlasty2.6.4). The 'Phenotype' column indicates whether the sampled individual possessed a pure species or hybrid phenotype, and capital letters in parentheses next to C. penicillata $\times$ C. geoffroyi category are specific phenotype classifications following Figure 5 in Fuzessy et al. (2014). The 'mtDNA Genome Lineage' column indicates phylogenetic classification of the mitogenome of the sampled individual. The 'Sampling Location' column indicates where each individual was sampled. Nearest cities are located for individuals sampled from the wild, and facilities are indicated for individuals sampled in captivity. The Guarulhos Municipal Zoo is located in Guarulhos, São Paulo, Brazil; CRC (Callitrichid Research Center) is located in Omaha, Nebraska, US; NEPRC (New England Primate Research Center, no longer in operation) was located in Southborough, Massachusetts, US; CPRJ (Centro de Primatologia do Rio de Janeiro) is located in Guapimirim, Rio de Janeiro, Brazil; CEMAFAUNA (Centro de Conservação e Manejo de Fauna da Caatinga) is located in Petrolina, Pernambuco. Abbreviations for Brazilian states in the 'Sampling Location' column are as follows: Espírito Santo (ES), Minas Gerais (MG), Rio de Janeiro (RJ), São Paulo (SP). DF is the Brazilian Federal District. (NA=No data Available). Table S2. Each cell lists individuals that possess the same mtDNA haplotypes. Table $\mathbf{S 3 .}$ Organization of the C. aurita mitogenome based on 16,471 sequenced bases of individual BJT065 (Accession number MT041703). Table S4. Divergence times for Callithrix species and select nodes (MRCA = Most recent common ancestor; values in brackets $=95 \%$ highest posterior density). Node names follow major node designations shown in Figure S3 as capital letters. Table S5. BMM posterior probabilities for Fig. 4 nodes. Location abbreviations follow Fig. 4. Table S6. Summary of record numbers for collected samples that have been entered into the Brazilian CGEN SISGEN sample database (ES=Espírito Santo, MG=Minas Gerais, PE= Pernambuco, RJ=Rio de Janeiro, SP=São Paulo).

Additional file 2: Figure S1. Maximum-likelihood (ML) tree showing phylogenetic relationships among Callithrix haplotypes as calculated from mitogenome sequences. Numbers at nodes indicate bootstrap support for a given node, otherwise node bootstrap support was 100\%. Haplotype colors at tips correspond to the 'Species and Hybrid Phenotypes' legend, and indicate phenotypes associated with each given haplotype.

Figure S2. Bayesian tree showing phylogenetic relationships among Callithrix species and hybrid haplotypes from mitogeomes sequences. Numbers at nodes indicate posterior probability for a given node, otherwise node posterior probability was 1 . Haplotype colors at tips correspond to the 'Species and Hybrid Phenotypes' legend, and indicate phenotypes associated with each given haplotype. Figure S3. BEAST tree showing phylogenetic relationships and divergence ages in million years (Ma) among Callithrix haplotypes and other New World primates as calculated from mitogeome sequences. Major nodes are identified by capital letters, and blue bars at all nodes indicate 95\% highest posterior densities (HPD) of divergence times. Haplotype colors at tips correspond to the 'Species and Hybrid Phenotypes' legend, and indicate phenotypes associated with each given haplotype.

\section{Acknowledgements}

We would like to thank the Callitrichid Research Center, the Golden Lion Tamarin Association, CEMAFAUNA, Rio de Janeiro Primatology Center, the Guarulhos Municipal Zoo, the Beagle Lab at UFV, and many biologists, field technicians, veterinarians, and other individuals that made this research possible. We would like to thank two anonymous reviewers for insightful comments on a previous version of this work.

\section{Authors' contributions}

JM formulated the idea for the study, collected samples, obtained funding, conducted wet and dry laboratory work, and wrote the original manuscript. RAC provided study guidance, and logistical support. NHAC provided field assistance and logistical support. JAD provided study guidance, and logistical support. CM assisted in phenotypic identification of hybrids. CSI gave access and provided logistical support to collect samples from animals kept at Guarulhos Zoo. SBM provided logistical support and veterinary assistance to collect samples from animals kept at the Rio de Janeiro Primatology Center. AN gave assistance with data processing. PAN gave access and provided logistical support to collect samples from animals kept at CEMAFAUNA.
LCMP gave access and provided logistical support to collect samples from animals kept at CEMAFAUNA. AP gave access and provided logistical support to collect samples from animals kept at CPRJ. CRRM and DZ were major contributors in writing the manuscript. DLS performed DNA extractions, methodological optimization, and carried out PCR. ACS was a major contributor in writing the manuscript, provided study guidance, and logistical support. CR gave assistance in data processing, carried out divergence analysis, gave significant guidance and input in the development of this study. All authors read and approved the final manuscript.

\section{Funding}

This work was supported by a Brazilian CNPq Jovens Talentos Postdoctoral Fellowship (302044/2014-0), a Brazilian CNPq DCR grant (300264/2018-6), an American Society of Primatologists Conservation Small Grant, a Marie-Curie Individual Fellowship (AMD-793641-4) and an International Primatological Society Research Grant for JM. The funding agencies had no roles in study design, data collection and analysis, decision to publish, or preparation of the manuscript. Open Access funding enabled and organized by Projekt DEAL.

\section{Availability of data and materials}

Newly sequenced and annotated Callithrix mitogenomes have been deposited in NCBI GenBank. Accession numbers for each sequence are given in Table S1.

\section{Declarations}

\section{Ethics approval and consent to participate}

Tissues were collected under the approval of the ASU Institutional Animal Care and Use Committee Animals (ASU IACUC, protocols \#11-1150R, 15144R), Brazilian Environmental Ministry (SISBIO protocols \#47964-2 and \#28075-2), and a CPRJ internal review. Biological tissue sampling complied with all institutional, national, and international guidelines.

\section{Consent for publication}

Not applicable.

\section{Competing interests}

The authors declare that they have no competing interests.

\section{Author details}

${ }^{1}$ Primate Genetics Laboratory, German Primate Center, Leibniz Institute for Primate Research, Göttingen, Germany. ${ }^{2}$ Instituto de Medicina Tropical de São Paulo, Universidade de São Paulo, São Paulo, SP, Brazil. ${ }^{3}$ School of Life Sciences and The Biodesign Institute, Arizona State University, Tempe, AZ, USA. ${ }^{4}$ Ecologia, Epidemiologia e Medicina da Conservação, Departamento de Medicina Veterinária, Unilavras, Lavras, MG, Brazil. ${ }^{5}$ Department of Animal Biology, Federal University of Viçosa, Viçosa, MG, Brazil. ${ }^{6}$ Guarulhos Municipal Zoo, Guarulhos, SP, Brazil. ${ }^{7}$ Centro de Primatologia do Rio de Janeiro, Guapimirim, RJ, Brazil. ${ }^{8}$ Programa de Interunidades em Biotecnologia, Instituto de Ciências Biomédicas, Universidade de São Paulo, São Paulo, SP, Brazil. ' SScientific Platform Pasteur, Universidade de São Paulo, São Paulo, Brazil. ${ }^{10}$ Programa de Pós-Graduação, Ciências da Saúde e Biológicas, Universidade Federal do Vale do São Francisco, Petrolina, PE, Brazil.

${ }^{11}$ Laboratório de Ecologia e Conservação de Mamíferos, Departamento de Biologia, Universidade Federal de Lavras, Lavras, MG, Brazil. ${ }^{12}$ Centro de Conservação e Manejo de Fauna da Caatinga, Universidade Federal do Vale do São Francisco, Petrolina, PE, Brazil. ${ }^{13}$ Laboratório das Ciências Ambientais, Centro de Biociências e Biotecnologia, Universidade Estadual do Norte Fluminense, Campos dos Goytacazes, RJ, Brazil. ${ }^{14}$ Núcleo de Pesquisas em Ciências Biológicas - NUPEB, Federal University of Ouro Preto, Ouro Preto, MG, Brazil. ${ }^{15}$ School of Human Evolution and Social Change, Arizona State University, Tempe, AZ, USA. ${ }^{16}$ Institute of Human Origins, Arizona State University, Tempe, AZ, USA. ${ }^{17}$ Center for Evolution and Medicine, Arizona State University, Tempe, AZ, USA. ${ }^{18}$ Cognitive Ethology Laboratory, German Primate Center, Leibniz Institute for Primate Research, Göttingen, Germany. ${ }^{19}$ Leibniz Science Campus Primate Cognition, Göttingen, Germany. ${ }^{20}$ Department of Primate Cognition, Georg-August-University, Göttingen, Germany. ${ }^{21}$ Gene Bank of Primates, German Primate Center, Leibniz Institute for Primate Research, Göttingen, Germany. 
Received: 24 August 2020 Accepted: 15 March 2021 Published online: 06 April 2021

\section{References}

1. Finstermeier K, Zinner D, Brameier M, Meyer M, Kreuz E, Hofreiter M, Roos C. A mitogenomic phylogeny of living primates. PLoS One. 2013;8(7):e69504. https://doi.org/10.1371/journal.pone.0069504.

2. Malukiewicz J, Boere V, Fuzessy LF, Grativol AD, De Oliveira I, Pereira LC, et al. Natural and anthropogenic hybridization in two species of eastern Brazilian marmosets (Callithrix jacchus and C. penicillata). PLoS ONE. 2015; 10(6):e0127268.

3. Perelman P, Johnson WE, Roos C, Seuanez HN, Hovarth JE, Moreira AM, et al. A molecular phylogeny of living primates. PLoS Genet. 2011;7(3): e1001342. https://doi.org/10.1371/journal.pgen.1001342.

4. Buckner JC, Lynch-Alfaro JW, Rylands AB, Alfaro ME. Biogeography of the marmosets and tamarins (Callitrichidae). Mol Phylogenet Evol. 2015;82B:413-25.

5. Rylands AB, Coimbra-Filho AF, Mittermeier RA. The systematics and distributions of the marmosets (Callithrix, Callibella, Cebuella, and Mico) and Callimico (Callimico) (Callitrichidae, Primates). In: Ford SM, Porter LM, Davis LC, editors. The smallest anthropoids: the marmoset/Callimico radiation. New York: Springer; 2009. p. 25-61. https://doi.org/10.1007/978-1-4419-02 93-1_2.

6. Malukiewicz J. A review of experimental, natural, and anthropogenic hybridization in Callithrix marmosets. Int J Primatol. 2019;40(1):72-98. https://doi.org/10.1007/s10764-018-0068-0.

7. Moraes AM, Vancine MH, Moraes AM, de Oliveira Cordeiro CL, Pinto MP Lima AA, Culot L, Silva TSF, Collevatti RG, Ribeiro MC, Sobral-Souza T. Predicting the potential hybridization zones between native and invasive marmosets within Neotropical biodiversity hotspots. Global Ecol Conserv. 2019;20:e00706. https://doi.org/10.1016/j.gecco.2019.e00706.

8. Vale CA, Neto LM, Prezoto F. Distribution and invasive potential of the black-tufted marmoset Callithrix penicillata in the Brazilian territory. Sci Plena. 2020;16:052401.

9. Carvalho RS, Bergallo HG, Cronemberger C, Guimarães-Luiz T, Igayara-Souza CA, Jerusalinsky L, et al. Callithrix aurita: a tiny primate on the edge of extinction in the Brazilian Atlantic Forest. Neotrop Primates. 2018;24:1-8.

10. Silva FFR, Malukiewicz J, Silva LC, Carvalho RS, Ruiz-Miranda CR, Coelho FAS, et al. A survey of wild and introduced marmosets (Callithrix: Callitrichidae) in the southern and eastern portions of the state of Minas Gerais, Brazil. Primate Conserv. 2018;32:1-18.

11. Carvalho RS. Conservação do saguis-da-serra-escuro (Callithrix aurita (Primates)) - Analise molecular e colormetrica de populações do gênero Callithrix e seus híbridos: PhD dissertation, Universidade do Estado do Rio de Janeiro; 2015

12. Melo F, Bicca-Marques J, Ferraz DS, Jerusalinsky L, Mittermeier RA, Oliveira L, et al. Callithrix aurita. In: The IUCN Red List of Threatened Species; 2019. p. e. T3570A17936433. https://doi.org/10.2305/IUCN.UK.2019-3.RLTS.T3570A1793 6433.en. Downloaded 13 Feb 2020

13. Rylands AB, Ferrari SF, Mendes SL. Callithrix flaviceps. In: The IUCN Red List of Threatened Species; 2008. p. e.T3571A9951402. https://doi.org/10.2305/ IUCN.UK.2008.RLTS.T3571A9951402.en. Downloaded 13 Feb 2020.

14. Zinner D, Arnold ML, Roos C. The strange blood: natural hybridization in primates. Evol Anthropol. 2011;20(3):96-103. https://doi.org/10.1002/evan.20301.

15. Zinner D, Wertheimer J, Liedigk R, Groeneveld LF, Christian RC. Baboon phylogeny as inferred from complete mitochondrial genomes. Am J Phys Anthropol. 2013;150(1):133-40. https://doi.org/10.1002/ajpa.22185.

16. Chown SL, Hodgins KA, Griffin PC, Oakeshott JG, Byrne M, Hoffmann AA. Biological invasions, climate change and genomics. Evol Appl. 2015;8(1):2346. https://doi.org/10.1111/eva.12234.

17. Castro JA, Picornell A, Ramon M. Mitochondrial DNA: a tool for population genetics studies. Int Microbiol. 1998;1(4):327-32.

18. Brown WM, George M Jr, Wilson AC. Rapid evolution of animal mitochondrial DNA. Proc Natl Acad Sci U S A. 1979;76(4):1967-71. https:// doi.org/10.1073/pnas.76.4.1967.

19. Mundy NI, Pissinatti A, Woodruff DS. Multiple nuclear insertions of mitochondrial cytochrome b sequences in callitrichine primates. Mol Biol Evol. 2000;17(7):1075-80. https://doi.org/10.1093/oxfordjournals. molbev.a026388.

20. Schneider $\mathrm{H}$, Bernardi JAR, da Cunha DB, Tagliaro $\mathrm{CH}$, Vallinoto $\mathrm{M}$, Ferrari SF, Sampaio I. A molecular analysis of the evolutionary relationships in the
Callitrichinae with emphasis on the position of the dwarf marmoset. ZoolScr. 2012:41:1-10.

21. Tagliaro CH, Schneider MPC, Schneider H, Sampaio IC, Stanhope MJ. Marmoset phylogenetics, conservation perspectives, and evolution of the mtDNA control region. Mol Biol Evol. 1997;14(6):674-84. https://doi.org/10.1 093/oxfordjournals.molbev.a025807.

22. Tagliaro CH, Schneider MPC, Schneider H, Sampaio I, Stanhope M. Molecular studies of Callithrix pygmaea (primates, Platyrrhini) based on transferrin intronic and ND1 regions: implications for taxonomy and conservation. Genet Mol Biol. 2000;23(4):729-37. https://doi.org/10.1590/S1415-47572 000000400006

23. Malukiewicz J, Boere V, Fuzessy LF, Grativol AD, French JA. De Oliveira e Silva I, et al. hybridization effects and genetic diversity of the common and black-tufted marmoset (Callithrix jacchus and Callithrix penicillata) mitochondrial control region. Am J Phys Anthropol. 2014;155(4):522-36. https://doi.org/10.1002/ajpa.22605.

24. Malukiewicz J, Hepp CM, Guschanski K, Stone AC. Phylogeny of the jacchus group of Callithrix marmosets based on complete mitochondrial genomes. Am J Phys Anthropol. 2017;162(1):157-69. https://doi.org/10.1002/ajpa.23105.

25. Dos Reis M, Gunnell GF, Barba-Montoya J, Wilkins A, Yang Z, Yoder AD. Using phylogenomic data to explore the effects of relaxed clocks and calibration strategies on divergence time estimation: primates as a test case. Syst Biol. 2018;67(4):594-615. https://doi.org/10.1093/sysbio/syy001.

26. Springer MS, Meredith RW, Gatesy J, Emerling CA, Park J, Rabosky DL, Stadler T, Steiner C, Ryder OA, Janečka JE, Fisher CA, Murphy WJ. Macroevolutionary dynamics and historical biogeography of primate diversification inferred from a species supermatrix. PLoS One. 2012;7(11): e49521. https://doi.org/10.1371/journal.pone.0049521.

27. Rogers J, Gibbs RA. Applications of next generation sequencing primate genomics: emerging patterns of genome content and dynamics. Nat Rev Genet. 2014;15(5):347-59. https://doi.org/10.1038/nrg3707.

28. Kinzey WG. Distribution of primates and forest refuges. In: Prance GT, editor. Biological diversification in the tropics. New York: Columbia University Press; 1982. p. $455-82$

29. Turchetto-Zolet AC, Pinheiro F, Salgueiro F, Palma-Silva C. Phylogeographical patterns shed light on evolutionary process in South America. Mol Ecol. 2013;22(5):1193-213. https://doi.org/10.1111/mec.12164.

30. Fuzessy LF, Silva IO, Malukiewicz J, Silva FFR, Pônzio MC, Boere V, Ackermann RR. Morphological variation in wild marmosets (Callithrix penicillata and C. geoffroyi) and their hybrids. Evol Biol. 2014;41(3):480-93. https://doi.org/10.1007/s11692-014-9284-5.

31. Ruiz-Miranda CR, Affonso AG, Martins A, Beck B. Distribuição do sagui (Callithrix jacchus) nas areas de ocorrência do mico-leão-dourado (Leontopithecus rosalia) no estado do Rio de Janeiro. Neotrop Primates. 2000;8:98-100.

32. Frehse FA, Braga RR, Nocera GA, Vitale JRS. Non-native species and invasion biology in a megadiverse country: scientometric analysis and ecological interactions in Brazil. Biol Invasions. 2016;18(12):3713-25. https://doi.org/10.1 007/s10530-016-1260-9.

33. Ribeiro MC, Metzger JP, Martensen AC, Ponzoni FJ, Hirota MM. The Brazilian Atlantic Forest: how much is left, and how is the remaining forest distributed? Implications for conservation. Biol Conserv. 2009;142(6):1141-53. https://doi.org/10.1016/j.biocon.2009.02.021.

34. Ribeiro MC, Martensen AC, Metzger JP, Tabarelli M, Scarano F, Fortin MJ. The Brazilian Atlantic Forest: a shrinking biodiversity hotspot. In: Zachos F, Habel J, editors. Biodiversity hotspots. Berlin: Springer; 2011. p. 5-21. https://doi. org/10.1007/978-3-642-20992-5_21.

35. Cortés-Ortiz L, Roos C, Zinner D. Introduction to special issue on primate hybridization and hybrid zones. Int J Primatol. 2019;40(1):1-8. https://doi. org/10.1007/s10764-019-00076-z.

36. Crispo E, Moore J, Lee-Yaw J, Gray S, Haller B. Broken barriers: humaninduced changes to gene flow and introgression in animals. BioEssays. 2011;33(7):508-18. https://doi.org/10.1002/bies.201000154.

37. Oliveira LC, Grelle CEV. Introduced primate species of an Atlantic Forest region in Brazil: present and future implications for the native fauna. TCS. 2012;5(1):112-20.

38. Todesco M, Pascual M, Owens G, Ostevik K, Moyers B, Hübner S, et al. Hybridization and extinction. Evol Appl. 2016;9(7):892-908. https://doi.org/1 0.1111/eva.12367.

39. Detogne N, Ferreguetti AC, Mello JFF, Santana MC, Dias AC, da Mota NCJ, et al. Spatial distribution of buffy-tufted-ear (Callithrix aurita) and 
invasive marmosets (Callithrix spp.) in a tropical rainforest reserve in southwestern Brazil. Am J Primatol. 2017;79(12):e22718. https://doi.org/1 0.1002/ajp.22718.

40. Detogne N. O sagui-da-serra-escuro (Callithrix aurita) e os saguis invasores no Parque Nacional da Serra dos Órgãos, RJ, Brasil: distribuição espacial e estratégias de conservação: Master's thesis, Universidade do Estado do Rio de Janeiro; 2015

41. Allendorf F, Leary R, Spruell P, Wenburg J. The problems with hybrids: setting conservation guidelines. TREE. 2001;16:613-22.

42. McFarlane SE, Pemberton JM. Detecting the true extent of introgression during anthropogenic hybridization. Trends Ecol Evol. 2019;34(4):315-26. https://doi.org/10.1016/j.tree.2018.12.013.

43. Rhymer JM, Simberloff D. Extinction by hybridization and introgression. Annu Rev Ecol Syst. 1996;27(1):83-109. https://doi.org/10.1146/annurev. ecolsys.27.1.83.

44. Wolf DE, Takebayashi N, Rieseberg LH. Predicting the risk of extinction through hybridization. Conserv Biol. 2001;15(4):1039-53. https://doi.org/10.1 046/j.1523-1739.2001.0150041039.x.

45. Neves L, Bicca-Marques J, Jerusalinsky L, Mittermeier RA, Pereira DG, Rylands AB. Callithrix kuhlii. In: The IUCN red list of threatened species; 2019. p. e. T3575A17936243. https://doi.org/10.2305/IUCN.UK.2019-3.RLTS.T3575A1793 6243.en. Downloaded 30 Mar 2020.

46. Malukiewicz J, Boere V, Borstelmann de Oliveira MA, D'Arc M, Ferreira JVA, French J, Houman G, de Souza CAl, Jerusalinsky L, de Melo FR, ValençaMontenegro MM, Moreira SB, Silva IO, Pacheco FS, Rogers J, Pissinatti A, del Rosario R, Ross C, Ruiz-Miranda CR, Pereira LCM, Schiel N, da Silva FFR, Souto A, Šlipogor V, Tardif S. An introduction to the Callithrix genus and overview of recent advances in marmoset research: Preprints; 2020. p. 2020110256. https://doi.org/10.20944/preprints202011.0256.v2.

47. Tauer C, Stewart JF, Rodney W, Lilly CJ, Guldin JM, Nelson CD. Hybridization leads to loss of genetic integrity in shortleaf pine: unexpected consequences of pine management and fire suppression. J Forest. 2012; 110(4):216-24. https://doi.org/10.5849/jof.11-044.

48. Sambrook J, Russel DW. Molecular cloning. 3rd ed. Cold Spring Harbor: CSHL Press; 2001.

49. Dierckxsens N, Mardulyn P, Smits G. NOVOPlasty: de novo assembly of organelle genomes from whole genome data. Nucleic Acids Res. 2017;45:e18.

50. Maddison WP, Maddison D. Mesquite: a modular system for evolutionary analysis. Version 3.51. 2018. http://www.mesquiteproject.org. Accessed 17 Dec 2019.

51. Rozas J, Ferrer-Mata A, Sánchez-DelBarrio JC, Guirao-Rico S, Librado P, Ramos-Onsins SE, et al. DnaSP 6: DNA sequence polymorphism analysis of large datasets. Mol Biol Evol. 2017;34(12):3299-302. https://doi.org/10.1093/ molbev/msx248.

52. Nguyen LT, Schmidt HA, Haeseler A, Minh BQ. IQ-TREE: a fast and effective stochastic algorithm for estimating maximum-likelihood phylogenies. Mol Biol Evol. 2015;32(1):268-74. https://doi.org/10.1093/molbev/msu300.

53. Huelsenbeck JP. F Ronquist.. MRBAYES: Bayesian inference of phylogeny. Bioinformatics. 2001;17(8):754-5. https:/doi.org/10.1093/bioinformatics/17.8.754.

54. Ronquist F, Huelsenbeck JP. MRBAYES 3: Bayesian phylogenetic inference under mixed models. Bioinformatics. 2003;19(12):1572-4. https://doi.org/10.1 093/bioinformatics/btg180

55. Chernomor O, von Haeseler A, Minh BQ. Terrace aware data structure for phylogenomic inference from supermatrices. Syst Biol. 2016;65(6):997-1008. https://doi.org/10.1093/sysbio/syw037.

56. Kalyaanamoorthy S, Minh BQ, Wong TKF, von Haeseler A, Jermiin LS ModelFinder: fast model selection for accurate phylogenetic estimates. Nat Methods. 2017;14(6):587-9. https://doi.org/10.1038/nmeth.4285.

57. Minh $B Q$, Nguyen $M A$, von Haeseler A. Ultrafast approximation for phylogenetic bootstrap. Mol Biol Evol. 2013;30(5):1188-95. https://doi.org/1 0.1093/molbev/mst024

58. Gelman A, Rubin DB. Inference from iterative simulation using multiple sequences (with discussion). Stat Sci. 1992;7(4):457-72. https://doi.org/1 $0.1214 / s s / 1177011136$

59. Bouckaert R, Heled J, Kühnert D, Vaughan T, Wu CH, Xie D, Suchard MA, Rambaut A, Drummond AJ. BEAST 2: a software platform for Bayesian evolutionary analysis. PLoS Comp Biol. 2014;10(4):e1003537. https://doi.org/1 0.1371/journal.pcbi.1003537.

60. Drummond AJ, Ho SYW, Phillips MJ, Rambaut A. Relaxed phylogenetics and dating with confidence. PLoS Biol. 2006;4(5):e88. https://doi.org/10.1371/ journal.pbio.0040088.
61. Byrne H, Rylands AB, Carneiro JC, Lynch JWA, Bertulo F, Silva MNF, et al. Phylogenetic relationships of the New World titi monkeys (Callicebus): first appraisal of taxonomy based on molecular evidence. Front Zool. 2016;13(1): 10. https://doi.org/10.1186/s12983-016-0142-4.

62. Rambaut A, Suchard MA, Xie D, Drummond AJ. Tracer v1.6. 2014. http://bea st.bio.ed.ac.uk/Tracer. Accessed 17 Dec 2019.

63. Huson HD, Bryant D. Application of phylogenetic networks in evolutionary studies. Mol Biol Evol. 2006;23(2):254-67. https://doi.org/10.1093/molbev/ msj030.

64. Yu Y, Blair C, He XJ. RASP 4: ancestral state reconstruction tool for multiple genes and characters. Mol Biol Evol. 2020;37(2):604-6. https://doi.org/10.1 093/molbev/msz257.

65. Yu Y, Harris AJ, Blair C, He XJ. RASP (reconstruct ancestral state in phylogenies): a tool for historical biogeography. Mol Phylogenet Evol. 2015; 87:46-9. https://doi.org/10.1016/j.ympev.2015.03.008.

\section{Publisher's Note}

Springer Nature remains neutral with regard to jurisdictional claims in published maps and institutional affiliations.

Ready to submit your research? Choose BMC and benefit from

- fast, convenient online submission

- thorough peer review by experienced researchers in your field

- rapid publication on acceptance

- support for research data, including large and complex data types

- gold Open Access which fosters wider collaboration and increased citations

- maximum visibility for your research: over $100 \mathrm{M}$ website views per year

At $\mathrm{BMC}$, research is always in progress.

Learn more biomedcentral.com/submissions 